\title{
Evaluación de las características de calidad, bromatológicas y fermentativas in vitro a diferentes tiempos de fermentación láctica de ensilados de mango maduro
}

\author{
Assessment of quality, bromatological and in vitro fermentative characteristics at \\ different times lactic fermentation of ripe mango silage
}

\author{
Nicolás Torres Saladoㅁ, Marcelino Gómez Trinidad ${ }^{1}$, Paulino Sánchez-Santillán ${ }^{1,2}$, \\ Adelaido Rafael Rojas García ${ }^{1}$, María de los Ángeles Maldonado Peralta ${ }^{1}$, María \\ Benedicta Bottini Luzardo ${ }^{1}$
}

\section{Resumen}

\begin{abstract}
El objetivo del estudio fue evaluar las características de calidad, bromatológicas y fermentativas in vitro de ensilados de mango maduro entre 28 y 168 días de fermentación láctica (FL). Los silos en bolsa (20 kg) se elaboraron con $80.64 \%$ de mango, $11.38 \%$ de pasto pangola, $4.55 \%$ de rastrojo de maíz, $2.04 \%$ de melaza y $1.36 \%$ de urea. El tiempo de apertura de los silos fue a los 28 (T1), 44 (T2), 97 (T3), 113 (T4), 126 (T5), 140 (T6), 154 (T7) y 168 (T8) d de FL. Se determinó pH, ácido láctico, materia seca (MS), proteína cruda (PC), fibra detergente neutro (FDN), fibra detergente ácido (FDA), hemicelulosa, producción de biogás y metano $\left(\mathrm{CH}_{4}\right)$, nitrógeno amoniacal $\left(\mathrm{N}_{-} \mathrm{NH}_{3}\right)$, $\mathrm{pH}$ del medio, conteo de bacterias totales, degradación de la materia seca (DMS) y degradación de la fibra detergente neutro (DFDN). El análisis estadístico fue un diseño completamente al azar. El contenido de MS, $\mathrm{pH}$, FDA y hemicelulosa no mostraron diferencias por el tiempo de FL ( $p>0.05)$. T2 presentó mayor contenido de ácido láctico, sin diferencias con T1, T3 y T4 ( $>>0.05)$. T1 mostró mayor contenido de PC que T2, T4 y T6 ( $<<0.05)$, sin diferencias con el resto de los tratamientos $(\mathrm{p}>0.05)$. La producción de biogás acumulado no se afectó con el tiempo de FL del ensilado ( $\mathrm{p}>0.05$ ). La producción de $\mathrm{CH}_{4}$ a las $72 \mathrm{~h}$ de incubación fue menor para $\mathrm{T} 4$, sin diferencias con T1, T3 y T5 ( $>>0.05)$. La mayor DMS fue para T1, T2, T3, T7 y T8 $(p<0.05)$. La menor DFDN fue para T4 y T5 $(p<0.05)$. Bajo estas condiciones se concluye que el ensilado de mango maduro puede fermentarse lácticamente hasta por 168 días sin que se afecten sus características de calidad, bromatológicas y fermentativas in vitro.
\end{abstract}

Palabras clave: mango maduro, pasto pangola, ensilados, fermentación láctica, rumiantes

\footnotetext{
${ }^{1}$ Facultad de Medicina Veterinaria y Zootecnia No. 2, Universidad Autónoma de Guerrero, Cuajinicuilapa, Guerrero, México

${ }^{2}$ E-mail: sanchezsantillanp@gmail.com
}

Recibido: 16 de julio de 2020

Aceptado para publicación: 2 de enero de 2021

Publicado: 24 de abril de 2021 
The aim of this study was to evaluate the quality, bromatological and in vitro fermentation characteristics of ripe mango silage between 28 and 168 days of lactic fermentation (LF). The silos in bags ( $20 \mathrm{~kg}$ ) were made with $80.64 \%$ mango, $11.38 \%$ pangola grass, $4.55 \%$ corn stubble, $2.04 \%$ molasses and $1.36 \%$ urea. The opening time of the silos was at 28 (T1), 44 (T2), 97 (T3), 113 (T4), 126 (T5), 140 (T6), 154 (T7) and 168 (T8) $\mathrm{d}$ of LF. It was determined $\mathrm{pH}$, lactic acid, dry matter (DM), crude protein (CP), neutral detergent fibre (NDF), acid detergent fibre (ADF), hemicellulose, biogas and methane $\left(\mathrm{CH}_{4}\right)$ production, ammoniacal nitrogen $\left(\mathrm{N}-\mathrm{NH}_{3}\right), \mathrm{pH}$ of the medium, total bacteria count, dry matter degradation (DMD) and neutral detergent fibre degradation (NDFD). The statistical analysis was under a completely randomized design. The content of $\mathrm{DM}, \mathrm{pH}$, $\mathrm{ADF}$ and hemicellulose did not show differences by FL time of the silage ( $p>0.05)$. T2 presented higher lactic acid content, without differences with $\mathrm{T} 1, \mathrm{~T} 3$ and $\mathrm{T} 4(\mathrm{p}>0.05)$. T1 showed higher $\mathrm{CP}$ content than $\mathrm{T} 2, \mathrm{~T} 4$ and $\mathrm{T} 6(\mathrm{p}<0.05)$; without differences with the rest of the treatments $(\mathrm{p}>0.05)$. The accumulated biogas production was not affected by the FL time of the silage $(\mathrm{p}>0.05) . \mathrm{CH}_{4}$ production after $72 \mathrm{~h}$ of incubation was lower for $\mathrm{T} 4$, without differences with $\mathrm{T} 1, \mathrm{~T} 3$ and $\mathrm{T} 5$ ( $>>0.05$ ). The highest $\mathrm{DMD}$ was for $\mathrm{T} 1, \mathrm{~T} 2, \mathrm{~T} 3, \mathrm{~T} 7$ and T8 $(p<0.05)$. The lowest NDFD was for T4 and T5 $(\mathrm{p}<0.05)$. Under these conditions, it is concluded that ripe mango silages can be lactic fermented for up to 168 days without affecting their in vitro quality, bromatological and fermentative characteristics.

Key words: ripe mango, pangola grass, silage, lactic fermentation, ruminants

\section{INTRODUCCIÓN}

El principal estado productor de mango en México es Guerrero, al generar 21\% de la producción nacional con $385125 \mathrm{t}$ (SIAP, 2018). Las empresas industrializadoras de esta fruta generan volúmenes importantes de desechos o residuos como cáscaras, huesos, frutas dañadas o con problemas de madurez y calidad, todos los cuales representan una importante fuente de contaminación. Los desechos de la agroindustria se encuentran entre 28 y $43 \%$ del total del mango procesado (Guzmán et al., 2010; Sumaya-Martínez et al., 2012). Los desechos frutales almacenados sin tratamiento presentan inestabilidad y se fermentan rápidamente por efecto de la temperatura generando productos contaminantes (Cañeque y Sancha, 1998). Por otra parte, la estacionalidad de la producción del mango y los desechos generados por la agroindustria surgen como una opción de aprovecharlos en la alimentación de rumiantes en forma ensilada (Guzmán et al., 2010).
El ensilado es la conservación de forrajes frescos u otros alimentos con elevado contenido de humedad (Cañeque y Sancha, 1998), cuyo objetivo es la conservación del valor nutritivo del alimento durante el almacenamiento (Garcés et al., 2004). Las características del proceso de ensilado permiten conservar desechos agroindustriales (Valencia et al., 2011), incluyendo los del mango (Guzmán et al., 2010; Cavallini et al., 2015; Sánchez-Santillán et al., 2019). Una alternativa de ensilados con desechos frutales es la elaboración de silos en bolsa; los cuales deben hacerse rápidamente para conservar el máximo de los azucares para asegurar una fermentación láctica. Un ensilado con desechos frutales debe tener valores de $3.8 \pm 0.2$ de $\mathrm{pH}$, un contenido de ácido láctico promedio de $30 \mathrm{~g} \mathrm{~kg}^{-1}$ de MS, presencia nula de ácido butírico y menos de $25 \mathrm{~g} \mathrm{~kg}^{-1}$ de materia seca (MS) de ácido acético (Cañeque y Sancha, 1998). 
Hernández-Rodríguez (2017) evaluó la composición química y características fermentativas de ensilados elaborados en bolsa con mango maduro molido y heno de pasto pangola (Digitaria decumbens) como absorbente de humedad; mientras SánchezSantillán et al. (2019) publicaron las variables de calidad de ensilado, análisis bromatológico, producción de biogás, metano y características fermentativas in vitro de ensilados elaborados en bolsa con mango maduro y heno de pasto pangola, en ambos casos realizando la apertura de los silos con $21 \mathrm{~d}$ de fermentación. Por tanto, el objetivo del presente estudio fue evaluar las características de calidad, químicas y fermentativas in vitro de ensilados de mango maduro molido conservados mediante una fermentación láctica hasta por 168 días para establecer los cambios que ocurren durante la fermentación láctica.

\section{MATERIALES Y MéTOdOS}

\section{Lugar de Estudio}

El estudio se realizó en el Laboratorio de Nutrición Animal de la Facultad de Medicina Veterinaria y Zootecnia No. 2 de la Universidad Autónoma de Guerrero, ubicado en el municipio de Cuajinicuilapa, Guerrero, México.

\section{Elaboración de Silos}

El desecho del mango maduro se recolectó de la empacadora del municipio de Cuajinicuilapa, Guerrero. El ensilado estuvo compuesto por este desecho (80.64\%), además de heno de pasto pangola $(11.38 \%)$ con $120 \mathrm{~d}$ de rebrote, rastrojo de maíz (4.55\%), melaza de caña de azúcar $(2.04 \%)$ y urea $(1.36 \%)$. El mango maduro, el rastrojo de maíz y el heno se molieron en una trituradora de forraje (M.A.GRO ${ }^{\circledR}$ TR-3500) con una criba de $2.54 \mathrm{~cm}$. Se utilizaron bolsas de propileno $(80 \times 90 \mathrm{~cm})$ para preparar silos, en unidades de $20 \mathrm{~kg}$ según la metodología descrita por
Lorenzo-Hernández et al. (2019). Los silos se dejaron fermentar por 28 días a temperatura ambiente en una galera.

La evaluación de los silos (3 repeticiones por tiempo de fermentación) se llevó a cabo en ocho tiempos de fermentación láctica, los cuales constituyeron los tratamientos en estudio: $\mathrm{T} 1=28 \mathrm{~d}, \mathrm{~T} 2=44 \mathrm{~d}, \mathrm{~T} 3=97 \mathrm{~d}, \mathrm{~T} 4=$ $113 \mathrm{~d}, \mathrm{~T} 5=126 \mathrm{~d}, \mathrm{~T} 6=140 \mathrm{~d}, \mathrm{~T} 7=154$ y T 8 $=168 \mathrm{~d}$.

\section{Indicadores de Calidad}

En cada tratamiento se realizaron análisis para determinar la calidad de los ensilados. Para determinar el pH se utilizó la metodología descrita por Lorenzo-Hernández et al. (2019). El contenido de MS (método 930.15) se estimó según lo descrito por la AOAC (2005). El ácido láctico se determinó con la metodología de Kimberley y Taylor (1996) modificado por Lorenzo-Hernández et al. (2019).

\section{Análisis Bromatológico}

Las muestras de los ensilados se deshidrataron en una estufa (Riossa ${ }^{\circledR} \mathrm{HCF}-41$, México) a $60^{\circ} \mathrm{C}$ por $72 \mathrm{~h}$ y fueron molidas en un molino Thomas-Wiley Mill (Thomas Scientific ${ }^{\circledR}$, USA) con criba de $1 \mathrm{~mm}$ de diámetro. Se determinó el contenido de proteína cruda (PC; método 920.105), cenizas (Ce) y materia orgánica (MO; método 942.05) con los procedimientos descritos por la AOAC (2005). La fibra detergente neutro (FDN) y la fibra detergente ácido (FDA) se determinaron con el método descrito por van Soest et al. (1991). La hemicelulosa se calculó por diferencia entre FDN y FDA.

\section{Medio de Cultivo}

Se utilizó $30 \mathrm{ml}$ de líquido ruminal bovino fresco centrifugado durante $10 \mathrm{~min}$ a $12857 \times \mathrm{g}, 5 \mathrm{ml}$ de solución mineral I [6 g $\mathrm{K}_{2} \mathrm{HPO}_{4}$ (Sigma-Aldrich) en $1000 \mathrm{ml}$ de agua destilada], $5 \mathrm{ml}$ de solución mineral II [6 $\mathrm{g}$ 
$\mathrm{KH}_{2} \mathrm{PO}_{4}$ (Sigma-Aldrich) $+6 \mathrm{~g}\left(\mathrm{NH}_{4}\right)_{2} \mathrm{SO}_{4}$ (Merck) $+12 \mathrm{~g} \mathrm{NaCl}$ (Sigma-Aldrich) $+2.45 \mathrm{~g}$ $\mathrm{MgSO}_{4}$ (Sigma-Aldrich) $+1.6 \mathrm{~g} \mathrm{CaCl}-2 \mathrm{H}_{2} \mathrm{O}$ $\left(\right.$ Sigma-Aldrich $^{\circledR}$ ) en $1 \mathrm{~L}$ de agua destilada], $0.1 \mathrm{ml}$ de resarzurina a $0.1 \%$ (Sigma-Aldrich), $0.2 \mathrm{~g}$ de peptona de soya (Merck), $0.1 \mathrm{~g}$ de extracto de levadura (Sigma-Aldrich), 4 $\mathrm{ml}$ de solución cisteína-sulfido [2.5 g Lcisteína (Sigma-Aldrich) en $15 \mathrm{~mL}$ de $2 \mathrm{~N}$ $\mathrm{NaOH}$ (Meyer) + 2.5 g de $\mathrm{Na}_{2} \mathrm{~S}-9 \mathrm{H}_{2} \mathrm{O}$ (Merck) aforado en $100 \mathrm{ml}$ de agua destilada], $5 \mathrm{ml}$ de solución a $8 \%$ de $\mathrm{Na}_{2} \mathrm{CO}_{3}$ (Merck) y $52.6 \mathrm{ml}$ de agua destilada.

El medio se esterilizó durante $15 \mathrm{~min}$ en autoclave a $121^{\circ} \mathrm{C}$ y 15 psi (Sánchez-Santillán et al., 2016; Herrera-Pérez et al., 2018). El bovino se manejó de acuerdo con el reglamento interno de bioética y bienestar de la UAGro con fundamento en las normas oficiales (NOM062-ZOO-1999 y NOM-051-ZOO-1995).

\section{Biodigestores}

Los biodigestores se prepararon usando la metodología descrita por Torres-Salado et al. (2019), en la cual se cambió la fuente de carbono del biodigestor por uno de los tratamientos del presente estudio.

\section{Producción de Biogás y Metano $\left(\mathrm{CH}_{4}\right)$}

La producción de biogás a las 24, 48 y $72 \mathrm{~h}$ de incubación se midió mediante el desplazamiento del émbolo de una jeringa de vidrio (50 ml; BD Yale ${ }^{\circledR}$, Brasil), según lo descrito por Hernández-Morales et al. (2018). La producción de $\mathrm{CH}_{4}$ a las 24,48 y $72 \mathrm{~h}$ de incubación se midió con la metodología de Stolaroff et al. (2008) modificada por TorresSalado et al. (2018) y Herrera-Pérez et al. (2018).

\section{Características Fermentativas}

A las 72 de fermentación se determinaron las características fermentativas in vitro. Para nitrógeno amoniacal $\left(\mathrm{N}-\mathrm{NH}_{3}\right)$ se siguió la metodología de McCullough (1967) modificado por Herrera-Pérez et al. (2018). El
pH del medio se midió según lo descrito por Torres-Salado et al. (2019). La cantidad de bacterias totales se calculó según la metodología descrita por Sánchez-Santillán et al. (2016). La degradación de la materia seca (DMS) se calculó con la metodología descrita por Hernández-Morales et al. (2018) y Torres-Salado et al. (2019); mientras la degradación de la FDN (DFDN) fue según lo descrito por Hernández-Morales et al. (2018).

\section{Análisis Estadístico}

Las variables de $\mathrm{PC}, \mathrm{MS}, \mathrm{Ce}, \mathrm{pH}$ silo, MO, FDN, FDA, Hemicelulosa (3 repeticiones independientes), ácido láctico (6 repeticiones independientes), producción de biogás, $\mathrm{CH}_{4}, \mathrm{pH}$ del biodigestor, DMS, DFDN (5 repeticiones independientes), $\mathrm{N}_{-} \mathrm{NH}_{3}, \mathrm{y}$ conteo de bacterias (3 repeticiones independientes) se analizaron en un diseño completamente al azar usando el procedimiento GLM (SAS, 2011). La diferencia entre promedios fue con la prueba de Tukey $(\mathrm{p}<0.05)$.

\section{Resultados}

Las características fisicoquímicas de ensilados de mango maduro con diferentes tiempos de fermentación láctica se presentan en el Cuadro 1. El contenido de MS, pH, FDA y hemicelulosa no mostró diferencias significativas por el tiempo de conservación de los ensilados, obteniendo en promedio $35.89 \%$ de MS, pH de $3.92,31.91 \%$ de FDA y $24.18 \%$ de hemicelulosa. T2 presentó el mayor contenido de ácido láctico $(\mathrm{p}<0.05)$, sin diferencias con T1, T3 y T4 ( $>>0.05)$. Los tratamientos T1, T2, T3, T4, T5 y T6 no presentaron diferencias en el contenido de $\mathrm{Ce}$ ( $>0.05$ ), indicando que de los 28 a 140 días de fermentación láctica no se afectó el contenido de cenizas de los ensilados de mango maduro. El contenido de MO en T1, T2, T6, T7 y T8 fue relativamente mayor, aunque sin diferencias significativas ( $p>0.05$ ), lo cual indicó que los ensilados durante los primeros 
Cuadro 1. Características de calidad y bromatológicos de ensilados de mango maduro con diferentes tiempos de fermentación láctica

\begin{tabular}{cccccccccc}
\hline Tratamiento & MS & pH & Láctico & Ce & MO & FDN & FDA & Hemi & PC \\
\hline T1 & 35.20 & 3.89 & $9.27^{\mathrm{a}}$ & $9.00^{\mathrm{abc}}$ & $91.00^{\mathrm{abc}}$ & $56.12^{\mathrm{ab}}$ & 31.32 & 24.80 & $18.76^{\mathrm{a}}$ \\
T2 & 33.84 & 3.90 & $9.63^{\mathrm{a}}$ & $8.89^{\mathrm{abc}}$ & $91.11^{\mathrm{abc}}$ & $56.69^{\mathrm{ab}}$ & 31.74 & 24.95 & $17.19^{\mathrm{b}}$ \\
T3 & 36.63 & 3.93 & $6.87^{\mathrm{abc}}$ & $9.10^{\mathrm{ab}}$ & $90.90^{\mathrm{bc}}$ & $56.47^{\mathrm{ab}}$ & 31.94 & 24.53 & $17.76^{\mathrm{ab}}$ \\
T4 & 36.85 & 3.96 & $8.67^{\mathrm{ab}}$ & $9.16^{\mathrm{ab}}$ & $90.84^{\mathrm{bc}}$ & $55.72^{\mathrm{ab}}$ & 31.84 & 23.88 & $16.82^{\mathrm{b}}$ \\
T5 & 36.14 & 3.97 & $5.87^{\mathrm{bc}}$ & $9.51^{\mathrm{a}}$ & $90.49^{\mathrm{c}}$ & $56.58^{\mathrm{ab}}$ & 32.01 & 24.57 & $17.48^{\mathrm{ab}}$ \\
T6 & 36.34 & 3.91 & $5.49^{\mathrm{c}}$ & $7.95^{\mathrm{abc}}$ & $92.05^{\mathrm{abc}}$ & $57.39^{\mathrm{a}}$ & 32.74 & 24.65 & $16.80^{\mathrm{b}}$ \\
T7 & 36.71 & 3.89 & $4.03^{\mathrm{c}}$ & $6.81^{\mathrm{bc}}$ & $93.19^{\mathrm{ab}}$ & $55.23^{\mathrm{ab}}$ & 32.24 & 23.00 & $17.53^{\mathrm{ab}}$ \\
T8 & 35.40 & 3.92 & $6.29^{\mathrm{bc}}$ & $6.63^{\mathrm{c}}$ & $93.37^{\mathrm{a}}$ & $54.52^{\mathrm{b}}$ & 31.42 & 23.10 & $17.92^{\mathrm{ab}}$ \\
\hline
\end{tabular}

$a, b, c$ Valores promedio con distinta letra en una misma columna son diferentes $(p<0.05)$ $\mathrm{MS}=$ materia seca, $\% ; \mathrm{pH}=$ potencial de hidrógeno; Láctico = porcentaje de ácido láctico con respecto a la $\mathrm{MS} ; \mathrm{Ce}=$ cenizas, $\% ; \mathrm{MO}=$ materia orgánica, \%; FDN = fibra detergente neutro, $\% ;$ FDA = fibra detergente ácido, \%; Hemi = hemicelulosa, \%; PC = proteína cruda, \% $\mathrm{T} 1=28 \mathrm{~d}, \mathrm{~T} 2=44 \mathrm{~d}, \mathrm{~T} 3=97 \mathrm{~d}, \mathrm{~T} 4=113 \mathrm{~d}, \mathrm{~T} 5=126 \mathrm{~d}, \mathrm{~T} 6=140 \mathrm{~d}, \mathrm{~T} 7=154, \mathrm{~T} 8=168 \mathrm{~d}$

44 días de fermentación láctica mostraron el mismo contenido de MO que los ensilados que tenían de 140 a $168 \mathrm{~d}$. El contenido de FDN de los ensilados presentaron diferencias entre los 140 (T6) y 168 (T8) d de fermentación láctica $(\mathrm{p}<0.05)$, pero sin diferencias significativas con los demás tratamientos ( $\mathrm{p}>0.05)$. Los ensilados con $28 \mathrm{~d}$ (T1) de fermentación láctica mostraron mayor contenido de PC que los ensilados con 44 (T2), 113 (T4) y 140 d (T6) $(\mathrm{p}<0.05)$.

La producción acumulada de biogás y metano se presenta en el Cuadro 2. T7 y T8 mostraron la mayor producción de biogás a las $24 \mathrm{~h}$ de fermentación $(\mathrm{p}<0.05)$, del cual $20.78 \%$ corresponde a $\mathrm{CH}_{4}$. A las $48 \mathrm{~h}$ de fermentación, los ensilados de 97 a 126 d (T3, T4 y T5) de fermentación láctica mostraron la menor producción de biogás, respecto a T7 y T8 ( $<<0.05)$. En estos tratamientos, la fracción de $\mathrm{CH}_{4}$ promedió $18.70 \%$. A las 72 $\mathrm{h}$ de incubación, se observó que la produc- ción de biogás acumulado no se afectó con el tiempo de fermentación láctica del ensilado, toda vez que los promedios fueron estadísticamente similares a $\mathrm{T} 1(\mathrm{p}>0.05)$; mientras que la producción de $\mathrm{CH}_{4}$ a las $72 \mathrm{~h}$ de incubación fue menor para los ensilados de T4 $(p<0.05)$, aunque sin diferencias con T1, T3 y T5 (p>0.05; Cuadro 2).

La mayor DMS se mostró en los tratamientos T1, T2, T3, T7 y T8 $(\mathrm{p}<0.05)$ con un promedio de $71.55 \%$ DMS, indicando que los ensilados de 28 a $97 \mathrm{~d}$ y de 154 a $168 \mathrm{~d}$ de fermentación láctica mostraron mayor DMS que el resto de los ensilados. En contraste, la menor DFDN fue para T4 y T5 $(\mathrm{p}<0.05)$ al promediar 45.87\%; por lo que los ensilados con 113 y 126 d de fermentación láctica mostraron la menor DFDN, respecto al resto de los ensilados. Los ensilados con 113 d (T4) de fermentación láctica mostraron el mayor valor de $\mathrm{pH}$ del medio de cultivo a las $72 \mathrm{~h}(\mathrm{p}<0.05)$, en tanto que el mayor contenido de $\mathrm{N}_{-} \mathrm{NH}_{3}$ del 
Cuadro 2. Producción acumulada de biogás y metano a las $72 \mathrm{~h}$ en ensilados de mango maduro con diferentes tiempos de fermentación láctica

\begin{tabular}{ccccccc}
\hline & \multicolumn{3}{c}{$\begin{array}{c}\text { Biogás acumulado total } \\
\left(\mathrm{ml} \mathrm{g}^{-1} \mathrm{MS}\right)\end{array}$} & \multicolumn{3}{c}{$\begin{array}{c}\text { Metano acumulado total } \\
\left(\mathrm{ml} \mathrm{g}^{-1} \mathrm{MS}\right)\end{array}$} \\
\cline { 2 - 7 } & $24 \mathrm{~h}$ & $48 \mathrm{~h}$ & $72 \mathrm{~h}$ & $24 \mathrm{~h}$ & $48 \mathrm{~h}$ & $72 \mathrm{~h}$ \\
\hline T1 & $196.99^{\mathrm{bc}}$ & $254.66^{\mathrm{ab}}$ & $276.97^{\mathrm{abc}}$ & $38.75^{\mathrm{abc}}$ & $53.50^{\mathrm{ab}}$ & $60.03^{\mathrm{ab}}$ \\
T2 & $196.27^{\mathrm{bc}}$ & $257.37^{\mathrm{ab}}$ & $284.99^{\mathrm{ab}}$ & $44.37^{\mathrm{ab}}$ & $61.10^{\mathrm{a}}$ & $69.06^{\mathrm{a}}$ \\
T3 & $189.04^{\mathrm{cd}}$ & $245.03^{\mathrm{bc}}$ & $278.71^{\mathrm{abc}}$ & $32.43^{\mathrm{bc}}$ & $53.06^{\mathrm{ab}}$ & $61.07^{\mathrm{ab}}$ \\
T4 & $160.75^{\mathrm{d}}$ & $209.44^{\mathrm{c}}$ & $246.80^{\mathrm{c}}$ & $28.53^{\mathrm{c}}$ & $40.28^{\mathrm{b}}$ & $48.68^{\mathrm{b}}$ \\
T5 & $180.45^{\mathrm{cd}}$ & $232.36^{\mathrm{bc}}$ & $262.51^{\mathrm{bc}}$ & $36.43^{\mathrm{bc}}$ & $54.01^{\mathrm{ab}}$ & $63.22^{\mathrm{ab}}$ \\
T6 & $194.65^{\mathrm{bc}}$ & $255.09^{\mathrm{ab}}$ & $286.77^{\mathrm{ab}}$ & $37.93^{\mathrm{abc}}$ & $56.68^{\mathrm{a}}$ & $65.22^{\mathrm{a}}$ \\
T7 & $225.36^{\mathrm{ab}}$ & $287.04^{\mathrm{a}}$ & $311.38^{\mathrm{a}}$ & $51.22^{\mathrm{a}}$ & $65.91^{\mathrm{a}}$ & $72.00^{\mathrm{a}}$ \\
T8 & $231.05^{\mathrm{a}}$ & $284.37^{\mathrm{a}}$ & $311.65^{\mathrm{a}}$ & $43.61^{\mathrm{ab}}$ & $57.24^{\mathrm{a}}$ & $63.86^{\mathrm{a}}$ \\
\hline a,b,c Valores promedio con distinta letra en una misma columna son diferentes $(\mathrm{p}<0.05)$ \\
T1 = 28 d, T2 = 44 d, T3 = 97 d, T4 = 113 d, T5 = 126 d, T6=140 d, T7 = 154 y T8=168 d
\end{tabular}

medio de cultivo después de $72 \mathrm{~h}$ de fermentación fue para los ensilados con 28 (T1) y $44 \mathrm{~d}$ (T2) de fermentación láctica $(\mathrm{p}<0.05)$. El mayor conteo total de bacterias ruminales a las $72 \mathrm{~h}$ fue cuando se usó como sustrato ensilados con 28 (T1), 44 (T2) y 97 d (T3) de fermentación láctica $(\mathrm{p}<0.05$; Cuadro 3$)$.

\section{Discusión}

Las características de calidad de un ensilado condicionan el proceso de fermentación, por lo que se requiere un $\mathrm{pH}$ de 3.5 (Garcés et al, 2004), MS de 30 a $40 \%$ (SAGARPA, 2017) y de 8 a $12 \%$ de carbohidratos fermentables como sustrato para las bacterias acido lácticas homofermentativas y heterofermentativas (Anaya-Reza y LópezArenas, 2018). En este sentido, los valores de MS, pH y ácido láctico encontrados en el presente estudio de ensilados de mango maduro fermentados hasta por 168 días indican que sus características de calidad no se vieron afectadas.
Los contenidos de FDN y FDA en el presente estudio se deben a la inclusión de heno de pasto pangola y rastrojo de maíz, los cuales contienen hasta 70\% de FDN (de la Roza-Delgado, 2005). Estos elementos fueron incluidos porque el mango contiene de 79 a 94\% de humedad (Yahía et al., 2006; Sánchez-Santillán et al., 2019) y se requería de ingredientes que contrarrestaran dicha humedad. Las diferencias en el contenido de PC con lo reportado para ensilado de maíz (Ruiz et al., 2009) se debe a la inclusión de $1.36 \%$ de urea en este trabajo; dado que la urea contiene $286 \%$ de PC (NRC, 2007).

El contenido de MS y PC, así como el valor de $\mathrm{pH}$ fueron de $77.78,10.11$ y $84.52 \%$ mayores, además el contenido de ácido láctico, MO, FDN y FDA fueron 52.42, 0.96, 16.59 y $30.40 \%$ menores que lo reportado en ensilados de maíz (Ruiz et al., 2009). De otra parte, valores inferiores al presente estudio fueron reportados por Hernández-Rodríguez (2017) en MS, FDN, FDA, PC, Ce, ácido láctico y $\mathrm{pH}$ en ensilados elaborados con $60 \%$ 
Cuadro 3. Características fermentativas in vitro a las $72 \mathrm{~h}$ de incubación en ensilados de mango maduro con diferentes tiempos de fermentación láctica

\begin{tabular}{cccccc}
\hline & DMS & DFDN & $\mathrm{pH}$ & $\mathrm{N}-\mathrm{NH}_{3}$ & Bacteria \\
\hline T1 & $70.68^{\mathrm{abc}}$ & $65.64^{\mathrm{a}}$ & $6.72^{\mathrm{bc}}$ & $28.76^{\mathrm{a}}$ & $9.73^{\mathrm{ab}}$ \\
T2 & $72.48^{\mathrm{ab}}$ & $68.52^{\mathrm{a}}$ & $6.67^{\mathrm{bc}}$ & $26.19^{\mathrm{ab}}$ & $10.40^{\mathrm{a}}$ \\
T3 & $69.42^{\mathrm{abc}}$ & $59.87^{\mathrm{ab}}$ & $6.73^{\mathrm{b}}$ & $23.44^{\mathrm{bc}}$ & $8.93^{\mathrm{abc}}$ \\
T4 & $63.99^{\mathrm{c}}$ & $47.93^{\mathrm{bc}}$ & $6.80^{\mathrm{a}}$ & $24.10^{\mathrm{bc}}$ & $6.80^{\mathrm{c}}$ \\
T5 & $64.33^{\mathrm{c}}$ & $43.81^{\mathrm{c}}$ & $6.72^{\mathrm{bc}}$ & $24.17^{\mathrm{bc}}$ & $6.93^{\mathrm{c}}$ \\
T6 & $66.26^{\mathrm{bc}}$ & $61.74^{\mathrm{ab}}$ & $6.65^{\mathrm{c}}$ & $21.48^{\mathrm{c}}$ & $7.33^{\mathrm{bc}}$ \\
T7 & $71.74^{\mathrm{ab}}$ & $64.74^{\mathrm{a}}$ & $6.69^{\mathrm{bc}}$ & $23.84^{\mathrm{bc}}$ & $6.53^{\mathrm{c}}$ \\
T8 & $73.36^{\mathrm{a}}$ & $66.80^{\mathrm{a}}$ & $6.68^{\mathrm{bc}}$ & $23.77^{\mathrm{bc}}$ & $7.07^{\mathrm{c}}$ \\
\hline
\end{tabular}

$a, b, c$ Valores promedio con distinta letra en una misma columna son diferentes $(p<0.05)$ $\mathrm{T} 1=28 \mathrm{~d}, \mathrm{~T} 2=44 \mathrm{~d}, \mathrm{~T} 3=97 \mathrm{~d}, \mathrm{~T} 4=113 \mathrm{~d}, \mathrm{~T} 5=126 \mathrm{~d}, \mathrm{~T} 6=140 \mathrm{~d}, \mathrm{~T} 7=154$ y T8 = $168 \mathrm{~d}$ DMS = degradación de materia seca, \%; DFDN = degradación de fibra detergente neutro, \%; pH $=$ potencial de hidrogeno; $\mathrm{N}-\mathrm{NH}_{3}=$ nitrógeno amoniacal, $\mathrm{mg} \mathrm{dL}^{-1} ;$ Bacteria $=10^{8}$ células $\mathrm{mL}^{-1}$

de mango maduro, $35 \%$ de heno de pasto pangola, $3 \%$ de melaza de caña y $2 \%$ de urea.

La producción de biogás sirve como un indicador indirecto de la cantidad de carbohidratos disponibles para la fermentación. La producción de biogás de los ensilados se puede asumir a la disponibilidad de nutrientes para los microorganismos ruminales durante la fermentación y que la digestión de los carbohidratos produce $\mathrm{CO}_{2} \mathrm{y} \mathrm{CH}_{4}$ como producto de la fermentación (Elghandour et al., 2016; Posada et al., 2006); no obstante, resultados inferiores han sido publicados. Así, Lorenzo-Hernández (2017) reportó $69.77 \mathrm{ml}$ de biogás $\mathrm{g}^{-1}$ de MS en ensilados elaborados con $72.5 \%$ de residuos de calabaza, $22.5 \%$ de heno pangola, $3 \%$ de melaza y $2 \%$ de urea, lo que representó una producción de biogás acumulada a las $72 \mathrm{~h}$ de $304.86 \%$ menor al valor observado en el presente estudio. Cavallini et al. (2015) reportaron $191 \mathrm{ml} \mathrm{g}^{-1}$ de MS en ensilados elaborados con mango maduro con $48 \mathrm{~h}$ de incubación, lo que representó $75.44 \%$ de lo producido en promedio por los ensilados evaluados. Aragadvay-Yung et al. (2015), por otra parte, obtuvieron 240 $\mathrm{ml} \mathrm{g}^{-1} \mathrm{MS}$ en ensilados elaborados con maíz, siendo $71.65 \mathrm{ml} \mathrm{g}^{-1} \mathrm{MS}$ menos que el ensilado de mango maduro con 168 días de fermentación láctica (T8).

El $\mathrm{CH}_{4}$ es un gas de efecto invernadero y representa una pérdida de energía para el animal. Los ensilados en el presente estudio contenían grandes cantidades de carbohidratos estructurales (pasto pangola y rastrojo de maíz), los cuales durante su fermentación producen ácido acético, $\mathrm{CO}_{2}$ e $\mathrm{H}_{2}$ como productos finales. Estos productos son utilizados por arqueas metanogénicas como sustratos para producir energía y producen $\mathrm{CH}_{4}$ como producto de dicha fermentación (Torres-Salado et al., 2018). Por consiguiente, es importante identificar cuanto $\mathrm{CH}_{4}$ corresponde del total de biogás producido, dado que a menor porcentaje sería menor la perdida de energía contenida en los ensilados (Araujo et al., 2011). Así, el ensilado con 113 días (T4) de fermentación láctica mostró que 
$\mathrm{CH}_{4}$ representó $17.74,19.23$ y $19.72 \%$ del total de biogás a las 24,48 y $72 \mathrm{~h}$ de incubación.

La degradación de la MS permite establecer la cantidad de nutrientes disponibles para los microorganismos, de modo que degradaciones superiores a $60 \%$ se relacionan con bajas concentraciones de fibras detergentes o alta digestibilidad de estas (Hernández-Morales et al., 2018); por lo que los ensilados con 168 días de fermentación láctica contienen fibras detergentes que no reducirían el consumo en el animal. Además, la degradación de la FDN permitió predecir que no se afectaría el consumo potencial de la materia seca, ya que se requieren degradaciones de FDN menores a $40 \%$ para estimar una afectación (Hoffman et al., 2007; Torres-Salado et al., 2019).

En los biodigestores del presente estudio se estimó en promedio una población de $10^{8}$ células $\mathrm{ml}^{-1}$ a las $72 \mathrm{~h}$ de incubación, valores inferiores a lo reportado por HerreraPérez et al. (2018), Almaraz-Buendía et al. (2019) y Torres-Salado et al. (2019), quienes reportaron concentraciones de $10^{9}$ células $\mathrm{ml}^{-1}$ a las $72 \mathrm{~h}$ de incubación en biodigestores inoculados con bacterias ruminales usando como sustratos rastrojo de maíz (Herrera-Pérez et al., 2018), pastos tropicales con $56 \mathrm{~d}$ de rebrote (Almaraz-Buendía et al., 2019) y heno de pasto cobra (Brachiaria hibrido CV. CIAT BR02/1794) con $56 \mathrm{~d}$ de rebrote (Torres-Salado et al., 2019). Así mismo, los valores de $\mathrm{pH}$ del presente estudio fueron mayores a 6 , por lo que no se afectó la adherencia de las bacterias celulolíticas al material celulósico (Nag-Jin et al., 2005; SánchezSantillán et al., 2016) ni se inhibió su crecimiento (Sánchez-Santillán y Cobos-Peralta, 2016). La concentración de $\mathrm{N}_{-} \mathrm{NH}_{3}$ en los biodigestores se asumen al contenido y la degradabilidad de la PC que contiene el ensilado (Herrera-Pérez et al., 2018), por lo que los valores reportados en el presente estudio se ubican dentro del rango reportado por Mehrez et al. (1977), quienes estimaron una concentración entre 20 y $27 \mathrm{mg} \mathrm{dl}^{-1}$ para alcanzar la máxima tasa de digestibilidad de la materia seca. Esto permite asumir que la población bacteriana probablemente se vea afectada por el tipo de sustrato usado en el biodigestor.

\section{Conclusiones}

- Los valores reportados de materia seca, $\mathrm{pH}$, ácido láctico, fibras detergentes, proteína cruda, cenizas y materia orgánica indicaron que los ensilados de mango maduro con una fermentación láctica hasta de 168 días no afectan sus características de calidad.

- El ensayo in vitro indicó que los ensilados de mango maduro tienen buena disponibilidad de carbohidratos estructurales y no estructurales.

\section{Agradecimientos}

A los alumnos Luis Gustavo Vélez Regino, Martín Pantalón de los Santos y Marcelino Gómez Trinidad por su participación en la realización del experimento, tanto en la elaboración de silos, como los análisis en el laboratorio. Este experimento fue financiado por el Cuerpo Académico UAGro-CA183 «Producción Sustentable de Rumiantes en el Trópico» de la Facultad de Medicina Veterinaria y Zootecnia No. 2 de la Universidad Autónoma de Guerrero.

\section{Literatura Citada}

1. Almaraz-Buendía I, García AM, Sánchez-Santillán P, Torres-Salado, Herrera-Pérez J, Bottini-Luzardo MB, Rojas-García AR. 2019. Análisis bromatológico y producción de gas in vitro de forrajes utilizados en el trópico seco mexicano. Arch Zootec 68: 260266. doi: 10.21071/az.v68i262.4145 
2. Anaya-Reza O, López-Arenas T. 2018. Design of a sustainable biorefinery for the production of lactic acid from sugarcane molasses. Rev Mex Ingen Quím 17: 243-259.

3. $\boldsymbol{A O A C}$. 2005. Official methods of analysis. $18^{\text {th }} \mathrm{ed}$. Association of Official Analytical Chemist. Arlington, VA, USA.

4. Aragadvay-Yungána $R G$, Rayas AAA, Heredia-Nava D, Estrada-Flores JG, Martínez-Castañeda FE, Arriaga-Jordán CM. 2015. Evaluación in vitro del ensilaje de girasol (Helianthus annuus L) solo y combinado con ensilaje de maíz. Rev Mex Cienc Pecu 6:315-327.

5. Araujo RC, Pires $A$, Mourão VGB, Abdalla AL, Sallam SMA. 2011. Use of blanks to determine in vitro net gas and methane production when using rumen fermentation modifiers. Anim Feed Sci Tech 166-167: 155-162. doi: 10.1016/j.anifeedsci.2011.04.009

6. Cañeque MV, Sancha SJL. 1998. Ensilados de forrajes y su empleo en la alimentación de rumiantes. Mundi-Presa. 257 p.

7. Cavallini J, Gil V, Ojeda A. 2015. Effect of ripening stage and presentation form on chemical composition and in vitro digestibility of mango fruit (Mangifera indica L). Livestock Research for Rural 27(4). [Internet]. Disponible en: http://www.lrrd.org/lrrd27/ 4/cava27059.html

8. de la Roza-Delgado B. 2005. E1 ensilado en zonas húmedas y sus indicadores de calidad. En: IV Jornada de Alimentación Animal. Pontevedra, España.

9. Elghandour MMY, Kholif AE, Lopez S, Mendoza GD, Odongo NE, Salem AZM. 2016. In vitro gas, methane and carbon dioxide productions of high fibrous diet incubated with fecal inocula from horses fed live yeasts in response to the supplementation with different yeast additives. J Equine Vet Sci 38: 6471. doi: 10.1016/j.jevs.2015.12.010
10. Garcés MAM, Berrio RL, Ruiz AS, Guillermo SLJ, Builes AAF. 2004. Ensilaje como fuente de alimentación para el ganado. Lasallista Inv 1(Suppl 1): 66-71.

11. Guzmán O, Lemus C, Bugarín J, Bonilla J. 2010. Ensilado de residuos de mango (Mangifera indica L) para la alimentación animal. Características fermentativas. Rev Comp Prod Porcina 17:218-224.

12. Hernández-Morales J, SánchezSantillán $P$, Torres-Salado $N$, Herrera-Pérez J, Rojas-García A, Reyes-Vázquez, I, Mendoza-Núñez $M A$. 2018. Composición química y degradaciones in vitro de vainas y hojas de leguminosas arbóreas del trópico seco de México. Rev Mex Cienc Pecu 9 (Suppl 1): 105-120. doi: 10.22319/ rmcp.v9i1.4332

13. Hernández-Rodríguez I. 2017. Composición química y evaluación in vitro de microensilados elaborados con mango y heno de pasto pangola. Tesis de Médico Veterinario. Cuajinicuilapa, Guerrero, México: Univ. Autónoma de Guerrero. $32 \mathrm{p}$.

14. Herrera-Pérez J, Vélez-Regino LG, Sánchez-Santillán P, Torres-Salado N, Rojas-García A, Maldonado-Peralta M. 2018. In vitro fermentation of fibrous substrates by water buffalo ruminal cellulolytic bacteria consortia. Rev MVZ Córdoba 23: 6860-6870. doi: 10.21897/ rmvz.1374

15. Hoffman PC, Lundberg KM, Bauman LM, Shaver RD, Contrearas-Govea FE. 2007. Digestibilidad in vitro del FDN (fibra detergente neutro): el debate de 30 vs 48 horas. Focus Forage 5: 1-4.

16. Kimberley A, Taylor C. 1996. A simple colorimetric assay for muramic acid and lactic acid. Appl Biochem Biotech 56: 49-54. doi: 10.1007/BF02787869

17. Lorenzo-Hernández $R$, Torres-Salado $N$, Sánchez-Santillán P, HerreraPérez J, Mayren-Mendoza FJ, Sali- 
nas-Ríos T, Rojas-García AR, et al. 2019. Evaluación de las características de calidad y bromatológicas de ensilados elaborados con residuos de calabaza (Cucurbita argyrosperma). Rev Int Contam Ambie 35: 957-963. doi: 10.20937/RICA.2019.35.04.14

18. Lorenzo-Hernández R. 2017. Análisis químico bromatológico y producción de gas in vitro de microensilados de Cucúrbita argyrosperma (calabaza) con heno de Digitaria decumbens (pangola). Tesis de Médico Veterinario. Cuajinicuilapa, Guerrero, México: Univ. autónoma de guerrero. $54 \mathrm{p}$.

19. McCullough H. 1967. The determination of ammonia in whole blood by a direct colorimetric method. Clin Chim Acta 17 (2): 297-304. https://doi.org/ 10.1016/0009-8981(67)90133-7

20. McCullough H. 1967. The determination of ammonia in whole blood by a direct colorimetric method. Clin Chim Acta 17: 297-304. doi: 10.1016/00098981(67)90133-7

21. Mehrez By AZ, Orskov ER, McDonald I. 1977. Rates of rumen fermentation in relation to ammonia concentration. Brit J Nutr 38: 37-443. doi: 10.1079/ bjn19770108

22. Nag-Jin C, Jee JIYI, Sejong O, Byoung-Chul K, HanJoon H, Young JK. 2005. Effect of $\mathrm{pH}$ and oxygen on conjugated linoleic acid (CLA) production by mixed rumen bacteria from cows fed high concentrate and high forage diets. Anim Feed Sci Tech 123124: 643-653. doi: 10.1016/j.anifeedsci.2005.04.054

23. [NOM-062-ZOO-1999] Norma Oficial Mexicana. Especificaciones técnicas para la producción, cuidado y uso de los animales de laboratorio. Servicio Nacional de Sanidad, Inocuidad y Calidad Agroalimentaria. [Internet]. Disponible en: https:/www.gob.mx/cms/uploads/ attachment/file/203498/NOM-062ZOO-1999_220801.pdf
24. [NOM-051-ZOO-1995] Norma Oficial Mexicana. Trato humanitario en la movilización de animales. Servicio Nacional de Sanidad, Inocuidad y Calidad Agroalimentaria. Internet]. Disponible en: https://fmvz.unam.mx/fmvz/p_estudios/apuntes_bioet/051zoo_movilizacion.pdf

25. NRC. 2007. Nutrient requirements of small ruminants (sheep, goats, cervids and new world camelids). Washington, DC: National Academy Press. 362 p.

26. Posada SL, Noguera R, Bolívar D. 2006. Relación entre presión y volumen para la implementación de la técnica in vitro de producción de gases en Medellín, Colombia. Rev Colomb Cienc Pec 19: 407-414.

27. Ruiz BO, Castillo Y, Anchondo A, Rodríguez C, Beltrán R, La OO, Payán J. 2009. Efectos de enzimas e inoculantes sobre la composición del ensilaje de maíz. Arch Zootec 58: 163172. doi: 10.21071/az.v58i222.5274

28. [SAGARPA] Secretaría de Agricultura, Ganadería, Desarrollo Rural, Pesca y Alimentación. 2017. Mango mexicano. Planeación agrícola nacional 20172030. [Internet]. Disponible en: https:// www.gob.mx/cms/uploads/attachment/ file/257078/Potencial-Mango.pdf

29. Sánchez-Santillán P, Cobos-Peralta MA, Hernández-Sánchez D, Alvarado AI, Espinosa-Victoria D, HerreraHaro JG 2016. Uso de carbón activado para conservar bacterias celulolíticas liofilizadas. Agrociencia 50: 575-582.

30. Sánchez-Santillán P, Cobos-Peralta $M A$. 2016. Producción in vitro de ácidos grasos volátiles de bacterias celulolíticas reactivadas y bacterias ruminales totales en sustratoscelulósicos. Agrociencia 50: 565-574.

31. Sánchez-Santillán P, Herrera-Pérez $J$, Torres-Salado N, AlmarazBuendýa I, Reyes-Vázquez I, RojasGarcía AR, Gómez-Trinidad M, et al. 2019. Chemical composition, and in vitro fermentation of ripe mango silage 
with molasses. Agroforest Syst 94: 15111519. doi: https://doi.org/10.1007/s10457019-00442-Z

32. SAS. 2011. SAS/STAT Software. Version 9.3. Cary, NC SAS, USA: Institute INC.

33. [SIAP] Servicio de Información Agroalimentaria y Pesquera. 2018. Anuario estadístico de la producción agrícola. [Internet]. Disponible en: https:/ /nube.siap.gob.mx/cierreagricola/

34. Stolaroff JK, Keit DW, Lowry GV. 2008. Carbon dioxide capture from atmospheric air using sodium hydroxide spray. Environ Sci Technol 42: 27282735. doi: $10.1021 / \mathrm{es} 702607 \mathrm{w}$

35. Sumaya-Martínez MT, Sánchez HML, Torres GG, García PD. 2012. Red de valor del mango y sus desechos con base en las propiedades nutricionales y funcionales. Rev Mex Agroneg 30: 828-833

36. Torres-Salado N, Sánchez-Santillán P, Rojas-García A, Herrera-Pérez J, Hernández-Morales J. 2018. Produc- ción de gases efecto invernadero in vitro de leguminosas arbóreas del trópico seco mexicano. Arch Zootec 67: 55-59. doi: 10.21071/az.v67i257.3347

37. Torres-Salado N, Sánchez-Santillán P, Rojas-García RA, Almaraz-Buendía I, Herrera-Pérez J, Reyes-Vázquez I. 2019. Producción de gas in vitro y características fermentativas de consorcios bacterianos celulolíticos ruminales de búfala de agua (Bubalus bubalis) y vaca Suiz-bu. Agrociencia 53: 145-159.

38. Valencia CA, Hernández BA, López $B L$. 2011. El ensilaje: ¿Qué es y para qué sirve? La ciencia y el hombre 24(2): 1-3.

39. van Soest PJ, Roberton JB, Lewis BA. 1991. Methods for dietary fiber, neutral detergent fiber, and nonstarch polysaccharides in relation to animal nutrition. $\mathrm{J}$ Dairy Sci 74: 3583-3597. doi: 10.3168/ jds.S0022-0302(91)78551-2

40. Yahía E, de jornelas JP, Ariza RF. 2006. El mango. México DF: Trillas. $224 \mathrm{p}$. 